\title{
College students' knowledge about sexually transmitted diseases in relation to sexual self-efficacy
}

\author{
Mychael Brooke Masters \\ West Virginia University
}

Follow this and additional works at: https://researchrepository.wvu.edu/etd

\section{Recommended Citation}

Masters, Mychael Brooke, "College students' knowledge about sexually transmitted diseases in relation to sexual self-efficacy" (2009). Graduate Theses, Dissertations, and Problem Reports. 805.

https://researchrepository.wvu.edu/etd/805

This Thesis is protected by copyright and/or related rights. It has been brought to you by the The Research Repository @ WVU with permission from the rights-holder(s). You are free to use this Thesis in any way that is permitted by the copyright and related rights legislation that applies to your use. For other uses you must obtain permission from the rights-holder(s) directly, unless additional rights are indicated by a Creative Commons license in the record and/ or on the work itself. This Thesis has been accepted for inclusion in WVU Graduate Theses, Dissertations, and Problem Reports collection by an authorized administrator of The Research Repository @ WVU. For more information, please contact researchrepository@mail.wvu.edu. 


\title{
COLLEGE STUDENTS' KNOWLEDGE ABOUT SEXUALLY TRANSMITTED DISEASES IN RELATION TO SEXUAL SELF-EFFICACY
}

\author{
By: Mychael Brooke Masters \\ A THESIS \\ Submitted to \\ The College of Human Resources and Education at West Virginia University
In partial fulfillment of the requirements for the degree of
Master of Arts
in
Educational Psychology \\ Department of Technology, Learning and Culture \\ Committee Chair: Carol Markstrom, Ph.D. \\ Kristin Moilanen, Ph.D. \\ Scott Cottrell, Ph.D. \\ Morgantown, West Virginia \\ 2009
}




\section{ABSTRACT \\ College Students’ Knowledge about Sexually Transmitted Diseases \\ in Relation to Sexual Self-Efficacy}

By

\section{Mychael Brooke Masters}

Resources associated with learning about sexually transmitted diseases (STDs) were investigated in relation to college students' sexual knowledge and sexual self-efficacy. Participants included 50 male and 67 female students ages 18, 19, and 20 at West Virginia University. Self-report surveys included the Sexually Transmitted Disease Knowledge Questionnaire (STD-KQ; Jaworski \& Carey, 2007), the Self-Efficacy Questionnaire (Cecil \& Pinkerton, 1998), and a measure developed by the investigator on resources used by college students to learn about STDs. No relationship was identified between resources used to learn about STDs and college students' sexual knowledge. However, sexual knowledge was a significant predictor of high levels of sexual self-efficacy to refuse sexual intercourse, question potential sex partners, and condom use. Findings in this study confirm previous research on sexual knowledge related to high levels of sexual self-efficacy. Also, information is discussed on extending research for future interventions related to sexual education and prevention of STDs on college campuses. 


\section{ACKNOWLEDGEMENTS}

First and foremost I would like to thank my parents, Mike and Jennifer Masters, if it was not for their constant love and support I would not be where I am today. I would also like to offer my sincerest gratitude to my thesis chairperson, Dr. Carol Markstrom, who has helped me through the entire process of writing a thesis. She has also provided me with great guidance and support throughout graduate school. Without her effort and encouragement I would have never completed this project. I would also like to thank my committee members Dr. Kristin Moilanen and Dr. Scott Cottrell for their unique insight and guidance through this process. I simply could not ask for more supportive or friendlier supervisors. Last but not least, I would also like to thank my classmates, who quickly became my closest friends throughout graduate school. 


\section{TABLE OF CONTENTS}

$\begin{array}{ll}\text { Abstract } & \text { ii }\end{array}$

Acknowledgements $\quad$ iii

Table of Contents $\quad$ iv

List of Tables $\quad$ vi

List of Figures vi

Chapter 1

$\begin{array}{ll}\text { Introduction } & 1\end{array}$

$\begin{array}{ll}\text { Overview } & 1\end{array}$

Statement of the Problem 1

Purpose of the Study 2

Chapter II

Review of Literature 3

Self-Efficacy Theory 3

STD Knowledge in Relation to Self-Efficacy and Sexual Behaviors $\quad 7$

$\begin{array}{ll}\text { Sources of Knowledge and Self-Efficacy } & 11\end{array}$

$\begin{array}{ll}\text { The Current Study } & 19\end{array}$

$\begin{array}{ll}\text { Hypothesized Model } & 20\end{array}$

Chapter III

$\begin{array}{ll}\text { Method } & 21\end{array}$

$\begin{array}{ll}\text { Participants } & 21\end{array}$

$\begin{array}{ll}\text { Procedures } & 22\end{array}$

$\begin{array}{ll}\text { Measures } & 22\end{array}$

Sources of Sexual Knowledge 22

STD Knowledge $\quad 23$

Sexual Self-Efficacy 24 
Chapter IV

Results

Correlational Analyses

Regression Analyses

27

Sexual Intercourse Refusal

Questioning Potential Sex Partners

Condom Use

Chapter V

$\begin{array}{ll}\text { Discussion } & 30\end{array}$

Interpretation of Results $\quad 30$

Study Limitation and Future Research 33

Conclusion $\quad 35$

References 37

Appendices

Appendix A: Participant Letter $\quad 40$

Appendix B: STD Survey (Sources of STD Knowledge) 41

Appendix C: STD Survey 42

Appendix D: Self-Efficacy Questionnaire 43-44 


\section{List of Tables and Figures}

Tables

Table 1. Scale Descriptives Table/Correlations 45

Table 2. Regression Table Refusal/Self-Efficacy 46

Table 3. Regression Table Potential Partner/Self-Efficacy 47

Table 4. Regression Table Condom Use/Self-Efficacy 48

Figures

$\begin{array}{lr}\text { Figure 1. Hypothesis Model } & 20\end{array}$

Figure 2. Interaction for Resources and Sexual Knowledge 49 


\section{CHAPTER 1}

Introduction

Overview

This study focused on examining links between college students' sources of knowledge of sexually transmitted diseases (STDs) and their sexual self-efficacy. This study addressed college students' current knowledge according to their sources of learning about STDs during their first year in a college environment. Additionally, associations between sources of STD knowledge, actual knowledge, and college student sexual self-efficacy were examined.

\section{Statement of the Problem}

Sexually transmitted diseases are a debilitating problem among college students in the U.S. and around the world (Brewer, 1997). A study conducted by Weinstock et al. (2000) indicated that 18.9 million new cases of STDs occurred during the year of 2000. It is crucial to mention that out of the 18.9 million cases, 9.1 million adolescents and young adults ages 15-24 were affected. According to Gold (2004), college students have awareness of general knowledge concerning STDs; however, they tend to lack prevention practices. It is possible that many precollege and college students do not receive the education needed to prevent the spread of STDs. This problem is also evident in some of the previous literature related to low knowledge and selfefficacy scores. A large amount of studies have focused on risky sexual behaviors and STDs, however, the current study includes sexual self-efficacy in order to explore why college students behave as they do and what may be done in order to prevent future risk taking behaviors. It is also important to learn more about this topic in order to possibly refine the content of sexual education classes and other STD prevention programs. 


\section{Purpose of the Study}

The main goal of this study was to conduct further research on how sexual information resources and STD knowledge relate to sexual self-efficacy. This knowledge is needed to prevent the spread of these types of diseases and to potentially save young lives. A key component of the previous research described in this literature review focuses on self-efficacy theory. As stated earlier, self-efficacy involves feelings or motivations that an individual has about engaging in a specific behavior. In this particular study, self-efficacy will always refer to feelings or motivations about sexual behaviors. This topic is important because it may provide information about why college students may or may not engage in risky sexual behaviors. This may also explain existing gaps in literature related to low STD knowledge scores and sexual risk taking behaviors. Self-efficacy theory serves a large purpose in this study because it could provide answers about how to address the problems associated with STDs and risky sexual behavior. Lastly, a final purpose of this study was to gather information directly from college students about their knowledge of STDs and self-reported efficacy about sexual behavior. 


\section{CHAPTER 2}

Review of Literature

The review of literature focuses on self-efficacy theory, STD knowledge in relation to self-efficacy and sexual behaviors, and sources of STD knowledge in relation to self-efficacy. Related topics reviewed are intervention strategies based on educating college students about STDs and preventive action. This research is the primary focus of the review of literature because there is little, if any, existing literature about relations between sources of sexual knowledge and sexual self-efficacy. It is important to review past research on intervention strategies and sexual education because it may be useful in pinpointing gaps in research and promoting better education for future preventive action.

Self-Efficacy Theory

Research studies on self-efficacy were examined in order to gather more information about how college students may use their existing knowledge about STDs in order to exercise control over their sexual behaviors. Self-efficacy can be defined as having a sense of control over certain personal choices that an individual makes (Pearson, 2006). Self-efficacy is a part of social learning theory, which relates to a person's beliefs in how capable he or she is of performing specific actions that result in specific outcomes (Hogben \& Byrne, 1998). For example, social learning theory involves the concepts of observational learning or modeling. Individuals seeking the perceived reward for a particular behavior may follow healthy behaviors modeled by others. Likewise, the rewards associated with a certain behavior are supposed to reinforce that behavior (Hogben \& Byrne, 1998). Thus, if college students learn healthy sexual behavior through education and other models they may view a healthy lifestyle as a positive outcome. As a result, college students may practice safe sexual behavior because they possess high levels of sexual 
self-efficacy. Concerning the topic of college student knowledge of STDs related to sexual selfefficacy, self-efficacy explains variation in college students' perceived abilities to exercise control over their motivations, social environments, and sexual behaviors (Cecil \& Pinkerton, 1998). The current study will focus on sexual self-efficacy, which is an individual's self-efficacy specifically related to sexual behaviors, social environments, and motivations.

In order to understand specific traits of self-efficacious individuals, it is important to define how these individuals may behave. For example, individuals who have a strong sense of personal control may also believe that outcomes are a result of personal choices rather than a result of luck or chance. In other words, self-efficacious individuals believe that they are responsible for determining how they shape their own lives (Pearson, 2006). However, it is also important to make the distinction that self-efficacy is not the same as behavior. Self-efficacy is related to selfperception about an individual's confidence or expectation to engage or not engage in a behavior as described above.

In the current study, self-efficacy was examined relative to how college students use this sense of control or self-perceptions in order to make sexual decisions. To gain a better understanding of the connection between self-efficacy and sexual behaviors, it is necessary to review prior studies conducted on this topic. For example, according to Pearson (2006), adolescents' sexual decision making is affected by normative ideas about appropriate sexual roles for both men and women. In Pearson's (2006) study, data were examined from the National Longitudinal Study of Adolescent Health (Add Health) in order to determine whether personal control and self-efficacy were factors associated with sexual risks behaviors, such as not using a condom during sexual intercourse. Findings in this longitudinal study indicated that high levels of personal control and self-efficacy were associated with healthier and safer sexual behavior 
(Pearson, 2006). This finding about self-efficacy suggests that youth who possess high levels of sexual self-efficacy may make healthier lifestyle choices concerning their sexual behaviors than youth with low levels of sexual self-efficacy.

Another topic to consider relevant to the current study is self-efficacy related to peer communication. This type of communication may impact the reinforcement of healthy or unhealthy sexual behavior in college students. For example, self-efficacy and healthy communication about sexual behavior was the topic of a study by Goebel-Komala (2003). For their dissertation, the author conducted a survey on sexual behavior and peer communication among university students. The study used Akers' social learning model, which focuses on how individuals learn a specific behavior and how this behavior is reinforced by peers or other social groups. According to this model, the level of positive reinforcement will then determine if the behavior will continue. In this particular study, Akers' social learning model was used to determine if this theory would explain sexual behavior in university students. Akers' social learning model involves operant conditioning and modeling, which are learning mechanisms. Akers' created the term "differential reinforcement" to explain an individual's behaviors in relation to rewards or punishments experienced in the past. This theory emphasizes rewards or punishments based on social interactions. For example, if an adolescent interacted with a group of other adolescents who abstain from sexual activity, then he or she may abstain in order to gain the reward of being accepted by the group. Participants completed a questionnaire that involved items used to measure Akers' theoretical concepts (Goebel-Komala, 2003). For example, Goebel-Komala's (2003) study incorporates concepts used by Akers' in a previous study that involved differential reinforcement. Goebel-Komala's questionnaire consisted of items related to how participants felt their parents or peers would react if they used a condom during sexual 
intercourse. The results of this study indicated that the model was useful in terms of explaining variance in the number of sexual partners in the previous six months along with percentage of protected sex (Goebel-Komala, 2003). For example, results indicated that $77 \%$ of participants used condoms during sexual intercourse. Thus, because this model was useful in explaining the results listed above, it may be useful to consider this information in the current study. Results from this study are relevant to the current study because they may provide answers about college students' sexual self-efficacy and what motivates these individuals to engage in safe or risky sexual behaviors.

Self-efficacy related to sexual behavior was also the topic for a study conducted by Denson, Voight, and Eisenman (1994). This study incorporated the use of a self-efficacy scale in order to determine the role of self-efficacy of university students concerning HIV/AIDS sexual risk taking behavior. The results of this study revealed that students with high self-efficacy did not report that risk taking behaviors were interesting to them, such as sharing needles, having multiple sex partners, and using drugs to enjoy sex. In other words, students with high selfefficacy did not necessarily engage in or express the intent to engage in the risk taking behaviors described above.

In a similar study, Peterson and Gabany (2001) investigated the use of a condom selfefficacy scale in order to determine the degree of confidence students had in using condoms during sexual intercourse. Results of this study indicated that university students who had not visited an STD clinic were not as likely to use condoms during sexual intercourse as students who had visited an STD clinic. This finding may be relevant to sexual self-efficacy because it suggests that college students who have been treated for an STD were more likely to avoid risk taking sexual behaviors in the future. In other words, the negative experience of contracting and 
possibly treating STDs may help increase youths' sexual self-efficacy. Results for this study also indicated that students with a higher degree of self-efficacy were more likely to use condoms consistently.

In summary of this section, each of these studies suggests that higher levels of selfefficacy or confidence in performing a specific sexual behavior are associated with healthier types of sexual behavior. It is also important to note that although the current study does not explicitly study sexual behaviors, the studies described above offer an argument for the importance of sexual self-efficacy in preventing sexual risk behavior among college students. Other factors may also influence healthy or unhealthy sexual behavior, such as knowledge about STDs, which will be discussed in the next section.

\section{STD Knowledge in Relation to Self-Efficacy and Sexual Behaviors}

In the previous section, self-efficacy was discussed in order to highlight the importance of this construct in association with sexual behavior. It is also important to understand the level of sexual knowledge that college students possess and how this is associated with their sexual self-efficacy. Thus, the following section will focus specifically on how STD knowledge or lack thereof may impact college student sexual self-efficacy and sexual behaviors.

STD knowledge is important to discuss relative to sexual self-efficacy because it may provide answers about how much and what types of STD knowledge college students need in order to have high levels of sexual self-efficacy. College student sexual knowledge and sexual behavior was the topic of a study conducted by Strader and Beaman (1991). The goal of the study was to make a comparison between two different groups of participants concerning knowledge about STDs. The two groups consisted of randomly-selected college students and STD clinic patients of the same age. This study used the Theory of Reasoned Action (TRA). This 
model states that in order to influence a behavior, significant beliefs about the target behavior must be identified. This model was specifically used to study beliefs about condom use in the two groups of participants. The two groups were compared on their knowledge of STDs, sexual behavior, and intentions to engage in sexual behavior. The data were assessed in order to determine how participants made decisions to use condoms during sexual intercourse. Additionally, data were also assessed to determine if these decisions were based on previous sexual knowledge (Strader \& Beaman, 1991). The results of this study revealed that $87 \%$ of college students were sexually active and had fewer sexual partners in a 30 day period compared to the STD clinic patients. However, for both groups in the six month study period, the mean number of sexual partners was the same. Sixty percent of the college student sample used condoms compared to $32 \%$ in the STD clinic group. Also, there were no statistical differences between the groups in relation to overall knowledge of HIV/AIDS (Strader \& Beaman, 1991). The Strader and Beaman (1991) study provides indicators for how sexual knowledge may directly impact sexual behavior or sexual self-efficacy. The results of this study showed that college students in comparison to STD clinic patients were more likely to use condoms during sexual intercourse. This could be due to the fact that college students have learned more useful information about preventative behaviors which may lead to higher levels of sexual self-efficacy.

Another study concerning knowledge about STDs was carried out among Turkish university students. Çok, Gray, and Ersever (2001) wanted to examine the relationship between sexual behavior, knowledge, attitudes, perceptions of risk, and HIV/AIDS. Over 500 students in Ankara, Turkey, completed a survey assessing these listed sexual variables, as well as sexual behaviors and sexual communication patterns. Students reported moderate levels of knowledge about the transmission and prevention of HIV/AIDS. Also, participants reported significant 
misconceptions about HIV/AIDS. Results of this study show that one third of the participants were sexually active with limited safe sex behaviors. Additionally, regardless of history of sexual activity, students' perceptions of their own personal risk related to contracting the disease were low. Students reported having gained general knowledge about HIV/AIDS through media, communicating with peers, and sexual education courses. Also, participants indicated that they still engaged in risky sexual behaviors despite being informed about HIV/AIDS through these resources. Participants' attitudes toward HIV/AIDS did not change significantly due to increased HIV/AIDS awareness through the resources listed above. For example, $79 \%$ of participants indicated that HIV/AIDS awareness did not significantly improve their attitudes about engaging in preventative behaviors. Implications for these perceptions and behaviors were identified by the authors. In particular, the author suggested that students are not receiving adequate education pertaining to sexual knowledge and behaviors. The results suggest that students may be lacking general knowledge needed in order to engage in healthy sexual behaviors. Thus, the previous study can be used as an example for how STD knowledge directly relates to sexual behavior and sexual self-efficacy.

A similar study conducted by Gold (2004) examined habits, beliefs, and knowledge of college students related to STDs and safe sex. Previous literature reviewed in Gold's (2004) study on this topic indicated that compared to older adults, young adults and adolescents are at higher risk for contracting STDs. Descriptive data were collected among university students and Gold (2004) analyzed the data about college students' habits, knowledge, and beliefs about STDs. The results of this study indicated that high rates of STDs in this age group may be due to the fact that young adults and adolescents are more likely to have multiple sex partners, engage in unprotected sex, and select partners that are at higher risk of having an STD. Results of this 
study revealed that although student awareness of STDs was high, prevention practices were low. Thus, consistent condom use during sexual intercourse was rare. Gold (2004) concluded that sexually active college students were well informed about STDs, but that their prevention practices were inconsistent with their high level of knowledge (Gold, 2004).

The previous study argued that STD knowledge may not necessarily be a predictor of healthier sexual behaviors. Another study concerning sexual knowledge and behavior was conducted by Jones and Haynes (2006). This study focused on the association between young people's knowledge of sexually transmitted diseases and their sexual risk behavior. Participants in this study were 303 university students in the United Kingdom. Questionnaires were given to focus groups of university students to assess their level of knowledge about STDs and their related sexual behaviors. The results of the study show that participants had high levels of awareness about STDs, yet young people were still likely to engage in risky sexual behavior. Thus, no evidence was found to suggest that higher levels of STD awareness led to safer sexual behavior. As a result, it was concluded that raising awareness of STDs alone will not significantly reduce risky sexual behavior (Jones \& Haynes, 2006).

Again, the previous study argues that knowledge about STDs may not necessarily be an indicator of healthy sexual behavior or sexual self-efficacy. College students' perceptions of risky sexual behavior were evaluated in a study conducted by Seal and Agostinelli (1996). The study was conducted in order to understand more about college students' knowledge about behaviors that could lead to contraction of STDs. The study assessed the risky sexual behavior perceptions in a sample of single heterosexual college students, which consisted of 96 men and 161 women. The authors defined sexual risk in terms of having multiple sex partners, having one-time sexual encounters, and engaging in unprotected sex. Results indicated that participants 
may overestimate the probability that others engage in risky sexual activity and consequently contract STDs. This is evident through findings which concluded that both men and women were biased in their overestimates of others' risks of contracting STDs. Also, women were more likely than men to overestimate the likelihood of contracting an STD. This result may be an indication that participants in general were not aware of the risk factors associated with contracting an STD. In other words, participants overestimate the frequency or likelihood that others may contract STDs. Results of this study may be indicative of the possibility that college students do not possess adequate sexual knowledge in order to prevent sexual risk taking behaviors.

In summary, several studies described in this section found that college students do not possess high levels of sexual knowledge, nor do they engage in healthy sexual behavior (Strader \& Beaman, 1991; Çok et al., 2001). On the other hand, a few studies indicated that when students possessed high levels of STD knowledge, this type of knowledge did not necessarily predict healthy sexual behavior (Gold, 2004; Jones \& Haynes, 2006). In other words, regardless of sexual knowledge, students did not engage in healthy sexual behaviors. A few of the studies introduced scales to measure the likelihood of risky sexual behaviors. In these studies, most participants indicated that they were unlikely to use preventative action during sexual intercourse, such as using a condom. In the next section, sexual knowledge explicitly obtained from sexual education programs or sources of sexual knowledge will be discussed in order to examine college students' exposure to this type of knowledge through education in a college environment and how that relates to self-efficacy.

\section{Sources of Knowledge and Self-Efficacy}

The current study investigated a list of resources that college students may use in order to learn more about STDs (e.g., the internet, textbooks, and attending lectures about STDs). 
However, little is known about the impact of sources other than educational and intervention programs. Thus, there is a gap in existing literature that needs to be addressed by studying the resources listed above for potential STD prevention. A concept similar to sexual knowledge relevant to the current study is exposure to types of sexual knowledge, such as sex education courses and seminars. This concept can also be related to sexual self-efficacy because sexual education may encourage students to become more self-efficacious in terms of sexual behaviors. Education courses and seminars could be considered a source of sexual knowledge and selfefficacy because college students are being exposed to potential knowledge and behaviors through learning. For example, it may be possible for students to learn more about STDs through sex education courses and seminars than through other resources, such as peers. Thus, if students learn about STDs through education courses and seminars, then these students may possess high levels of STD knowledge.

Sexual education and prevention programs have been frequently discussed in the existing literature on college student sexual behavior. Although the current study does not include sexual attitudes or behaviors, it does include sexual self-efficacy. As mentioned earlier, this is how college students think that they may behave in specific sexual situations. In one such investigation, Gokengin and colleagues (2003) aimed to gather information on how much college students know about preventative behaviors in order to create sex education programs. Sexual knowledge, attitudes, and risk behavior of students were also factors assessed by Gokengin and colleagues (2003). The study was used to produce information about college students' knowledge of STDs. Sexual attitudes and behaviors were also evaluated to help adapt existing education programs. Gokengin and colleagues' (2003) study was conducted at Ege University in Turkey, with a sample of first and fourth year college students. All participants in the study 
completed a questionnaire created to assess sexual attitudes, behavior, history of STDs, and factors associated with sexual knowledge. Participants indicated higher levels of knowledge based on HIV and AIDS than other STDs. Additionally, students' knowledge about signs and symptoms of STDs were low. Participants mainly relied on media and peers as resources for knowledge of STDs. A majority of the students (84.7\%) reported that STD prevention was an individual's own responsibility. On average, scores for knowledge questions were low, and thus the authors concluded that student knowledge about STDs was generally insufficient. Study results suggested the need for STD control programs and school based sexuality programs for adolescents and young adults in order to increase their STD knowledge (Gokengin et al., 2003).

The next study also looked at how sexual education programs can directly benefit college students. Previous literature reviewed for the current study frequently indicated the need for more sexual education courses and prevention programs for college students. However, information concerning specific benefits that college students may gain from attending sex education courses has not yet been interpreted. The current study does not specifically attend to this issue, however; it may be useful to study patterns related to sexual education courses in order to gain more information about how college students are learning about STDs. Also, this topic may be crucial in determining how much college students know about STDs. As stated earlier, there are problems concerning high rates of STDs among college students. Thus, these problems may be indicative of the possibility that they are not receiving adequate sexual education.

Synovitz, Herbert, Kelley, and Carlson (2002) explored information about sexual education and its potential benefits, such as gaining useful knowledge in terms of STD prevention, for both college students and youth preparing to attend college. Some specific 
examples of STD prevention in the form of educating college students may include encouraging condom use or abstaining from sexual behaviors.

The purpose of this study was to look at problems concerning early sexual activity, teen pregnancy, and high rates of STDs in Louisiana pre-college and college students. Participants in this study consisted of 602 female and 313 male college students attending four different Louisiana state universities (Synovitz et al., 2002). Participants completed a survey which assessed 27 items related to sexual knowledge and 18 items relating to quality of previous sexual education courses. The authors predicted that high quality sexual education would lead to greater overall sexual knowledge. However, results revealed that the opposite of this was true in this investigation. Findings of the study indicated that high quality sexual education courses led to less overall sexual knowledge. This may be because college students are not interested in sex education courses. It is also a possibility that students are being presented with a large amount of information in a short period of time. Thus, it may be likely that college students do not remember what they have learned in sex education courses. Due to the results of this study, the author suggested that pre-college and college students need to participate in more adequate sexuality education programs in order to gain knowledge about responsible sexual behavior (Synovitz et al., 2002).

The previous studies discussed the need for college sex education courses and possible benefits associated with sex education. For example, Synovitz et al. (2002) proposed the idea that if college students were to participate in more adequate sexual education courses, they would possibly benefit by having more overall STD knowledge. However, the Synovitz et al. (2002) study was the only one that focused on the impact of sex education courses and seminars 
taken in the past. The next study differs from the previous two because it focused primarily on how one sex education seminar impacted college students' sexual behavior.

While conducting a study used to evaluate an intervention geared at encouraging sexual responsibility, Turner et al. (1994) assessed the effectiveness of a college sex education seminar at the University of Virginia. Participants in this study consisted of 786 first year college students. A survey was used to assess outcome measurements of knowledge and attitudes related to STDs after 3 months of participating in the program. After the seminar, results revealed that knowledge, attitude, and behavior scores were significantly higher for students enrolled in the seminar opposed to those who were not enrolled in the program. For instance, general knowledge about STDs increased, including knowledge of the signs and symptoms of STDs and the importance of using protection during sexual intercourse. In terms of behavior, this included higher levels of abstinence and more frequent contraception use. Also, results indicated that postintervention, students became more confident about using condoms or remaining abstinent (Turner et al., 1994). Thus, it appears that students gained knowledge about STDs after attending the seminar. In addition, students seemed to acquire healthier attitudes after the intervention, such as having more confidence to use a condom or remain abstinent.

In a similar study about sexual behavior change MacNair-Semands, Cody, and Simono (1997) created a college HIV pandemic and AIDS course, and evaluated its effectiveness in terms of college student knowledge, attitudes, and sexual behavior. The purpose of this course was to educate youth about HIV/AIDS. Participants were similar in age, gender, degree program, and were randomly assigned to an experimental or a control group. Participants in the experimental group were enrolled in the HIV and AIDS course, while the control group received no education on these topics. Variables assessed in the study consisted of student knowledge of 
those enrolled in the HIV course compared to the knowledge of students not enrolled in the course. A pre-test and a post-test were conducted to assess college student initial and subsequent knowledge related to HIV. Results revealed that at pre-test, over $80 \%$ of students reported having had intercourse regularly without a condom. Post-test results revealed that after completion of HIV course, students were more likely than those who had not completed the course to change risky sexual behavior. For instance, students were more likely to use a condom during sexual intercourse or question potential partners before sexual intercourse than they had been at pre-test. Thus, this study supports the idea that knowledge has a direct impact on self-reported behaviors. Also, after completion of this course, students in the experimental group felt less vulnerable to contracting HIV compared to students in the control group (MacNair-Semands et al., 1997).

In another educational intervention evaluation study, youths' attitudes toward high risk sexual behaviors were evaluated by Templeton and Wilson (1992). The goal of the study was to assess the effectiveness of an educational intervention module in terms of students' attitudes toward high risk sexual behaviors. This study was implemented in order to determine an effective educational technique in order to encourage healthy sexual behavior and potentially reduce the spread of STDs among first year college students. A survey was conducted among first year college students attending an all male liberal arts college. The survey was administered during the first two weeks of classes. A post-intervention survey was administered after a module on AIDS and STDs was presented. Results of the post-intervention survey indicated that participants were still likely to engage in risky sexual behaviors, such as not using a condom during sexual intercourse. Findings of this study were consistent with prior literature, which concluded that increasing knowledge does not necessarily reduce risky behavior. The author also indicated that education alone may not be enough to prevent high risk sexual behavior. This 
conclusion was based on the finding that students were still likely to engage in risky sexual behavior even after the AIDS and STDs module was presented (Templeton \& Wilson, 1992).

While sex education has been the topic of several of the previous articles, it remains unclear whether sex education is ultimately enough to prevent STDs. In a study about preventing risky sexual behaviors, Brewer (1997) pointed out that prior research conducted on STDs and college student sexual behavior suggest that students' sexual behavior is not affected by educational interventions alone. Thus, the purpose of Brewer's (1997) study was to combine an educational intervention along with skills training in an attempt to reduce high risk sexual behavior in college students. One hundred sixty-one college students participated in this study. Participants were assigned to one of three conditions, consisting of a no-treatment control group, an education-only intervention group, or an education plus behavioral training intervention group. Knowledge scores in the two education intervention groups increased after the intervention, and control group scores were not affected (Brewer, 1997). Students in the skills training course reported higher rates of sexual intercourse with use of condoms, followed by the education intervention group. Yet, these trends in behavior were not statistically significant group differences. This could have been the result of knowledge prior to the intervention, or because many participants had already established these behaviors prior to the intervention. Also, it is important to note that the education intervention and skills training course were each only conducted once. As a result, it is possible that the intervention was too brief to produce actual results. The researcher concluded that increased knowledge about STDs did not affect college student sexual behavior (Brewer, 1997).

Sex education was again the topic of a study on AIDS and fertility-related behavior by Baldwin, Whiteley, and Baldwin (1990). In order to assess the effectiveness of sexual education 
programs in general, a 10-week human sexuality course was created for university students. Participants were given questionnaires in order to evaluate effectiveness of the course. At the beginning of the course, student sexual behavior was assessed before any information was given on birth control, sexual behavior, and the AIDS virus. Three months after the course, the experimental group and a newly-recruited control group of students completed the preintervention questionnaire. The results of the questionnaire suggested that the experimental group had significant increases in general knowledge about AIDS compared to students in the control group. Additionally, a majority of the experimental group showed more selective behavior in their choice of sexual partners, and reported asking their partners more questions about AIDS related behaviors. However, some participants reported that sometimes they did not use condoms during sexual intercourse. The course also failed to reduce the number of sexual partners participants had after completion of the course and post intervention survey (Baldwin et al., 1990).

In a number of the studies discussed above, the main objective was to assess college students' current knowledge of STDs and then compare it to knowledge post intervention. The type and format of intervention in each of the studies was also similar. For example, several of the studies either implemented seminars or other forms of educational information concerning STD prevention. However, some of the studies only explored college student knowledge of STDs, and then suggested methods to improve this knowledge. The general consensus of some of these studies is that knowledge or education alone is not enough to prevent STDs or change risky sexual behavior. These studies are also similar in that they suggest that further research needs to be conducted on how to promote healthy sexual behavior among college students. In 
addition, these articles also present methods for future STD prevention programs and educational interventions.

\section{The Current Study}

The literature reviewed covered a wide range of topics such as sexual risk taking, knowledge about healthy sexual behavior, STDs, and self-efficacy related to sexual behavior. Each study was different yet some of the studies also shared similarities. For instance, these investigations concerning sexual risk taking, knowledge, and behavior often incorporated educational seminars or other means of educating participants. Results in these studies yielded similarities such as improvement in healthy sexual behavior after the completion of sex education seminars. On the other hand, some of the studies revealed no relations between subsequent sexual behavior and educational seminars. Additionally, other means of evaluating these issues were incorporated into the literature, such as the use of theoretical support for specific goals and findings to predict sexual risk taking and sexual behavior. As mentioned earlier, there are gaps in existing literature based on sources of STD knowledge. Current literature on STD knowledge has consistently relied on educational intervention strategies as a means for encouraging STD prevention. What is known about STD prevention is not sufficient in terms of precisely locating which resources students utilize in order to learn about STDs. Instead of creating more educational seminars and lectures for college students, it may be useful to research STD resources that are being overlooked by researchers and practitioners, such as resources that are researched independently by college students. If these resources are identified in future research, it may be possible to improve outlets for learning about STDs.

Based on ideas taken from the previous literature, it is hypothesized that when college students have more sources of sexual STD knowledge, then they will have more overall 
knowledge about STDs. Thus, it is likely that there will be a positive relation between these two variables. Secondly, it was hypothesized that when college students have greater STD knowledge, they will also have higher levels of sexual self-efficacy. Lastly, it was hypothesized that when college students use more resources to learn about STDs and have more sexual STD knowledge, then they will have higher levels of sexual self-efficacy. The hypothesis is illustrated in Figure 1 below.

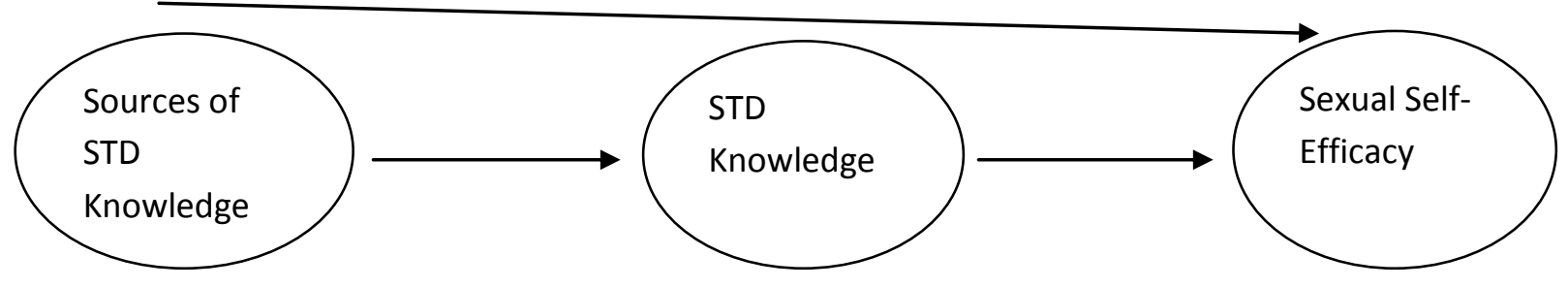

Figure 1

Hypothesized Model 


\section{CHAPTER 3}

Methods

The current study evaluated how college students gain knowledge about STDs and how this knowledge relates to sexual self-efficacy. The independent variable in this study was sources of STD knowledge, and the dependent variable was sexual self-efficacy, with STD knowledge as a potential moderator variable. The goal of the study was to gain a better understanding about what college students know about STDs and if this knowledge is related to their sexual selfefficacy. Data for the study was collected through the format of a survey. Students may potentially gain knowledge about STDs through research on the internet, peers, personal experience, seminars, textbooks, and speaking with a physician about STDs. As a result, college students that are required to learn about STDs or personally seek information themselves may gain more overall knowledge about STDs and prevention. Also, college students who gain both information and knowledge about STDs may be more likely to have higher levels of sexual selfefficacy.

\section{Participants}

Participants in this study consisted of 50 male and 67 female college students attending West Virginia University (WVU). Questionnaires were given to students enrolled in the program of Families Across the Lifespan Child Development and Family Studies (CDFS 110) and in the program of Learning Strategies for Academic Success Educational Psychology (EDP 101). These classes were chosen because a large number of students are enrolled in these courses. Also, both CDFS 110 and EDP 101 serve as general education requirements at WVU, and students from a variety of majors enroll in those courses. Participants consisted of university students ages 18,19 , and 20 (average age $=18.96$ years, $\mathrm{SD}=.71)$. This age range was targeted 
in the study in order to understand what new students at the university are learning about STDs after completing a few semesters at the university.

\section{Procedures}

Participants were asked to complete a survey during class time. There was no incentive for participation, and students were not penalized if they did not want to participate in the study. The survey was composed of three different measures, including items on sources of STD knowledge, a measure of STD knowledge, and a measure of sexual self-efficacy. The survey was distributed by one researcher. The researcher explained that questionnaires would be completed anonymously. Additionally, the questionnaire took approximately 20 minutes to complete and the researcher provided assistance to participants as needed. The survey was approved by the Institutional Review Board (IRB) at WVU. A cover letter for participants can be found in Appendix A.

\section{Measures}

The following measures were chosen because they appeared to be valid measures of the constructs needing to be measured for this study.

\section{Sources of sexual knowledge}

The first survey was created by the investigator and consists of items related to how students acquire information about STDs. The title of the survey was "Sources of STD Knowledge" (see Appendix B). As described earlier, new university students may be required to learn about STDs or explore other options for learning about themselves, such as the internet and textbooks. The list of resources was created by using information gathered by the author from students and professors/researchers at WVU. For example, several students and instructors were asked about basic resources that would be useful for gaining knowledge about STDs. This 
section of the survey was composed of 11 learning resources in order for the participant to check all that apply to his or her past experience in learning about STDs, such as attending STD seminars. One point was assigned for each resource that the participant checked on the list, for a total of 11 possible points on the measure and a range of possible scores from $0-11$.

\section{STD knowledge}

The Sexually Transmitted Diseases (STD) Questionnaire was used to evaluate students' knowledge about STDs (Ehrhardt, Krumboltz, \& Koopman, 2006; see Appendix C). The STD questionnaire was used in a prior study conducted on STD risk reduction intervention with college students (Ehrhardt et al., 2006). Questions in this measure were answered as either true, false, or “don't know." For instance, student participants were presented with questions such as "Genital herpes is caused by the same virus as HIV, "true or false?" Students were given one point for answering items correctly and zero points for answering incorrectly or "don't know." The questionnaire consists of 27 items and total scores for this measure range from 0 to 27 . Information provided by Jaworski and Carey (2007) indicated that this measure has adequate internal consistency. Reliability of the questionnaire was calculated by the Pearson product correlation coefficient. Test-retest reliability was $r=.88, p<.01$ (Jaworski \& Carey, 2007). According to Ehrhardt and colleagues (2006), results revealed that the questionnaire is reliable with a Cronbach's alpha of 0.86 . Also, data indicated that the questionnaire is stable in groups over time ( 1 week $r=.92 ; 2$ months $r=.85$ ) (Ehrhardt et. al., 2006). The Cronbach's alpha for the STD knowledge scale in this sample was .83 . 
Sexual self-efficacy. A previously validated measure of self-efficacy taken from a study conducted by Cecil and Pinkerton (1998) was also employed in the current study (see Appendix D). The measure assesses self-efficacy for three domains of protective sexual behavior. The three domains or subscales consisted of refusing sexual intercourse, using condoms, and questioning potential sexual partners. A number of items were used by Cecil and Pinkerton (1998) to assess participants' confidence in refusing sexual intercourse, questioning potential sexual partners about history of drug use, and his or her ability to use condoms. In particular, nine items are used to assess participants' confidence in their ability to refuse sexual intercourse. Also, participant confidence in questioning potential sexual partners is then assessed by five items. Lastly, eight items determine the participant's ability to obtain and use condoms. The participant then responds to the items according to how sure he or she would perform each indicated activity. For example, participants are asked "Could you resist sexual intercourse with someone you have known for a few days or less?" The participant would then indicate confidence in this situation by choosing a number ranging from 1 (a little sure) to 5 (very sure) (Cecil \& Pinkerton, 1998). Students were asked to respond to several items related to their confidence in the ability to refuse sexual intercourse in different settings. Cecil and Pinkerton (1998) mentioned that all three subscales exhibited good internal consistency, and convergent validity was demonstrated for the five item subscale. In addition, it is stated that the instrument appeared to be free of social desirability bias and was a reliable and valid means for assessing college student self-efficacy related to protective sexual behaviors (Cecil \& Pinkerton, 1998). Cronbach's alphas for subscales in the current study were .82 for refusing sexual intercourse, .88 for questioning potential sex partners and .85 for ability to use a condom during sexual intercourse. 


\section{Analytic Strategy}

Variables analyzed were sources of STD knowledge, sexual knowledge, total selfefficacy, ability to refuse sexual intercourse, potential to question sex partners, and ability to use a condom during sexual intercourse. The first hypothesis was "When college students have more sources of sexual STD knowledge, then they will have more overall knowledge about STDs." Secondly, it was hypothesized that when college students have greater STD knowledge, they will have higher levels of sexual self-efficacy. Lastly, it was hypothesized that "When college students use more resources to learn about STDs and have more sexual STD knowledge, then they will have higher levels of sexual self-efficacy." Bivariate correlations were used to assess each of the hypotheses listed above. Regression analyses were used in order to assess the last hypothesis concerning self-efficacy and STD knowledge. 


\section{CHAPTER 4}

Results

\section{Correlational Analyses}

Hypothesis one stated that when college students have more sources of STD knowledge, then they will have more overall knowledge about STDs (see Table 1). Thus, it was hypothesized that there would be a positive correlation between these two factors. Hypothesis one was not supported because it was revealed that there was no significant relationship between number of resources used to learn about STDs and sexual knowledge, $r(117)=.15, p>.05$. It was stated in the second hypothesis that when college students have greater STD knowledge, they will have higher levels of sexual self-efficacy. Self-efficacy was examined by the three subscales consisting of sexual intercourse refusal, questioning potential partners and condom use. There was a statistically significant positive correlation between sexual knowledge and ability to refuse sexual intercourse, $r(117)=.23, p<.05$. Individuals who reported higher levels of sexual knowledge also reported greater confidence in the ability to refuse sexual intercourse. There was also a statistically significant positive correlation between sexual knowledge and ability to question potential sex partners, $r(117)=.25, p<.01$. Individuals who reported higher levels of sexual knowledge also reported greater confidence in their ability to question potential sex partners. However, there was no significant association between sexual knowledge and ability to use a condom during sexual intercourse, $r(117)=.04, p<.05$. Finally, there was a positive correlation between overall self-efficacy and sexual knowledge, $r(117)=.24, p<.01$. Thus, individuals who reported higher levels of sexual knowledge also reported having higher levels of self-efficacy. 
In terms of resources used to learn about STDs, there was no significant relationship between number of resources and ability to refuse sexual intercourse, $r(117)=.06, p<.05$. On the other hand, there was a statistically significant positive correlation between number of STD resources and ability to question potential sex partners, $r(117)=.26, p<.01$. No significant relationship was reported between number of STD resources and ability to use a condom during sexual intercourse, $r(117)=.02, p<.05$. Lastly, there was a statistically significant positive correlation between number of STD resources and overall sexual self-efficacy, $r(117)=.24, p<$ .05 , which means that students who reported using more resources to learn about STDs were also likely to have higher sexual self-efficacy in terms of the three subscales described above. Regression Analyses

The last hypothesis stated, "When college students use more resources to learn about STDs and have more sexual STD knowledge, then they will have higher levels of sexual selfefficacy." Three regression analyses were used to test this hypothesis. In these analyses, participant sexual knowledge along with number of resources used to learn about STDs were regressed on the three self-efficacy subscales, i.e., the ability to refuse sexual intercourse, ability to question potential sex partners, and ability to use condoms during sexual intercourse.

Sexual intercourse refusal. In the first model, sexual knowledge along with number of resources used to learn about STDs accounted for a significant proportion of participants' ability to refuse sexual intercourse, $F(1,114)=6.39, p<.05, R^{2}=.05$ (see Table 2 ). High levels of sexual knowledge were associated with high levels of self-efficacy to refuse sexual intercourse. The addition of number of resources used to learn about STDs on the second step did not significantly improve the model, $\Delta F(1,113)=.07, p>.05, \Delta R^{2}=.001$. The number of resources did not predict refusal self-efficacy. The addition of the interaction between sexual knowledge 
and number of resources on the third step also did not improve the model significantly, $\Delta F$ $(1,112)=.10, p>.05, \Delta R^{2}=.001$. The interaction between sexual knowledge and the number of resources was not a significant predictor of sexual intercourse refusal.

Questioning potential partners. In the first step of the second model, sexual knowledge accounted for a statistically significant proportion of participants' ability to question potential sex partners, $F(1,114)=7.66, p<.01, R^{2}=.06$ (see Table 3 ). High levels of sexual knowledge were associated with high levels of potential self-efficacy. The addition of number of resources used to learn about STDs on the second step did significantly improve the model, $\Delta F(1,113)=$ $6.60, p<.05, \Delta R^{2}=.05$. High numbers of resources were predictive of high potential selfefficacy. The addition of the interaction between sexual knowledge and number of resources on the third step improved the model significantly, $\Delta F(1,112)=5.74, p<.05, \Delta R^{2}=.04$ (see Figure 2 for a depiction of the interaction). At high levels of knowledge, potential self-efficacy was high, regardless of the number of resources a participant had for sexual information. At low levels of knowledge, having few resources for sexual knowledge was indicative of the poorest levels of potential self-efficacy, having many resources was indicative of the highest levels of potential self-efficacy. As a result, this information supports the third hypothesis.

Condom use. In the third model, sexual knowledge did not account for a significant proportion of participants' ability to use a condom during sexual intercourse (see Table 4). Sexual knowledge was not associated with condom use self-efficacy. The addition of number of resources used to learn about STDs in the second step did not improve the model, $\Delta F(1,113)=$ $.03, p>.05, \Delta R^{2}=.00$. Number of resources was not associated with condom use self-efficacy. Finally, the addition of the interaction between sexual knowledge and number of resources on the third step did not improve the model significantly, $\Delta F(1,112)=1.00, p>.05, \Delta R^{2}=.01$. 
The interaction between sexual knowledge and number of resources did not explain variance in condom use self-efficacy. 


\section{CHAPTER 5}

\section{Discussion}

\section{Interpretation of Results}

As stated earlier, the first hypothesis was rejected because there was no significant relationship between sources of STD knowledge and overall sexual knowledge. However, there were some positive correlations between sexual knowledge and other factors, such as the ability to refuse sexual intercourse and ability to question potential sex partners. Concerning the second hypothesis, positive correlations were found between overall sexual knowledge and sexual selfefficacy. Also, there was support for the third hypothesis because there were positive associations in regression analyses between number of STD resources and overall sexual selfefficacy.

The first hypothesis stated that "When college students have more sources of sexual STD knowledge, then they will have more overall knowledge about STDs." Hypothesis one was not supported because results revealed that there was no significant relationship between number of resources used to learn about STDs and sexual knowledge. This could be due to the possibility that students are using STD resources which they have acquired, but are not gaining sufficient STD knowledge. For example, a student may attend a seminar about STDs, but forget the information soon after the seminar and thus would be unable to apply what they learned in reallife situations. Gokengin et al. (2003) reported comparable findings after college students completed a questionnaire focusing on STD knowledge and resources commonly accessed to gain STD knowledge. Results indicated that participants' knowledge about signs and symptoms of STDs were low. Additionally, STD resources commonly accessed by these students included peers and media. This finding is similar to findings in the current study and with hypothesis one 
because it suggests that STD resources accessed by college students are not adequate in terms of gaining useful sexual knowledge.

Secondly, it was hypothesized that "When college students have greater STD knowledge, they will have higher levels of sexual self-efficacy." Correlational and regression analyses provided support for hypothesis two because it was found that higher levels of knowledge resulted in higher levels of refusing sexual intercourse and questioning potential sex partners. This means that participants in the current study did not rely on knowledge for all aspects of sexual self-efficacy. For example, knowledge was not linked to ability to use a condom during sexual intercourse. This is also evident in previous literature related to the current study because several other studies found similar results. One particular study that included similar results was Baldwin et al., (1990). In this study, college students completed a sexuality course and reported incidences after completing the course in which they did not use condoms even though they had also reported gaining sexual knowledge. On the other hand, participants indicated that they were more likely to question potential sex partners about their sexual behavior after completing the sexuality course.

Lastly, it was hypothesized that "When college students use more resources to learn about STDs and have more sexual STD knowledge, then they will have higher levels of sexual self-efficacy." In terms of regression analyses relative to hypothesis three, it was sexual knowledge and not number of resources that significantly predicted participants' ability to refuse sexual intercourse. This finding was consistent with hypothesis two relative to sexual knowledge. Thus, students who reported high levels of knowledge also reported having the ability to refuse sexual intercourse. This may be indicative of the fact that students who have more knowledge about STDs may have the ability to resist risky sexual behaviors in terms of refusing intercourse. 
Turner et al., (1994) presented similar findings after conducting a college sex education seminar. After gaining more knowledge from the seminar, college students were more likely to abstain from engaging in sexual intercourse. On the other hand, resources used to learn about STDs did not significantly predict the ability to refuse sexual intercourse, nor was the interaction between resources used to learn about STDs and sexual knowledge significant.

Knowledge and number of resources used to learn about STDs were both significant predictors of the ability to question potential sex partners. Thus, students reported a greater likelihood to question potential sex partners when they had more resources to learn about STDs and had more knowledge of STDs. This finding provides some support for the second hypothesis because it suggests that students who have more sexual knowledge also have higher levels of sexual self-efficacy. This may be because students who have utilized more resources in order to learn more about STDs know more about how to question a potential sex partner. Also, these students may be more aware of risks involved if certain questions are not asked prior to engaging in sexual intercourse.

Finally, in both correlational and regression analyses, knowledge and number of resources used to learn about STDs were not significantly associated with the ability to use a condom during sexual intercourse nor was the interaction between these variables significant relative to use of a condom. In this case, the second and third hypotheses were not supported. This could be due to the fact that students in monogamous relationships do not feel the need to use condoms because they have established a trusting relationship with one partner. However, it is not known how many of the respondents were in monogamous relationships nor is it known, of those in such relationships, how many do not use condoms during sexual intercourse. This could be used as a separate explanation for condom non-use because young adults often stop 
using condoms after they commit to a long-term relationship. Furthermore, it may be that these students do have general knowledge about condom use, but choose not to protect themselves, regardless of their relationships status. Also, it is possible that both of these explanations could be true for different individuals, depending upon their unique circumstances.

Overall, possessing higher levels of sexual knowledge predicted higher levels of sexual self-efficacy. This was also a trend found in previous literature on sexual self-efficacy. For example, according to a study conducted by Strader and Beaman (1991), college students who were exposed to general knowledge about STDs were also more likely to possess higher levels of sexual self-efficacy than those who had not been exposed to this general knowledge.

Additionally, there are similarities between the current study and others related to sexual self-efficacy. For instance, a study by Denson et al. (1994) was conducted in order to determine university students' sexual self-efficacy in relation to HIV/AIDS. The results of this study revealed that students with high self-efficacy were not likely to express interest in risk taking behaviors such as sharing needles, having multiple sex partners, and using drugs to enjoy sex. This example is similar to the current study because it was found that students with higher levels of self-efficacy were more likely to question potential sex partners and refuse sexual intercourse. Study Limitations and Future Research

One of the limitations in this study was sample size. In past research conducted on this topic there were at least 200 participants. The sample for the current study included only 117 participants. Thus, in order to gain a wider range of results, it may have been helpful to have more students participate in the study. For example, more participants may have provided different responses in terms of STD resources and knowledge. This may have been helpful in gathering more accurate information about how college students are learning about STDs. Also, 
students may not have had interest in completing the survey. As a result, students may have completed the surveys quickly without truly considering the questions. Similarly, even though the STD survey was anonymous, students may have been apprehensive about providing factual information because this is a sensitive and personal topic. This is a problem because results may not be an accurate reflection of college students' actual behaviors. Future research on this topic needs to focus on making participants comfortable with sharing information on this topic. Perhaps research in the future could focus on offering more sex education courses to incoming first year students or providing confidential consultations with health or counseling professionals on campus.

In addition, items used to assess student sexual knowledge, such as the resource checklist, may not have been an accurate reflection of how students learn about STDs. For instance, students may not have checked some of the resources on the survey because they have not been exposed to them before. This limitation could possibly be reduced or eliminated in future research by having college students list resources that they have utilized in the past. This could be done by providing open-ended questions in addition to a resources checklist.

Future research on this topic needs to focus on additional means of collecting data from students. For example, it may be helpful to look at what college students know about STDs before entering a college environment. This may provide more information about what knowledge college students have or are lacking upon entrance to college. Perhaps there are other STD resources available on college campuses that could be included in the measure. Thus, it may be helpful to have access to information from health professionals, to gain more accurate information on how frequently STD resources are used. Also, it may be useful to talk with 
physicians or school counselors on college campuses to gain awareness about what resources are provided to the students.

\section{Conclusion}

The current study has shown that there are relationships between sexual knowledge and some aspects of sexual self-efficacy. For example, it was found that sexual knowledge is related to refusing sexual intercourse and questioning potential sex partners. On the other hand, it was found that number of resources used to learn about STDs was not related to sexual knowledge. Also, number of resources used to learn about STDs was not related to ability to use a condom or ability to refuse sexual intercourse. Previous research conducted on topics similar to the current study yielded similar findings in terms of resources, knowledge, and sexual self-efficacy as noted. As a result, it can be concluded that this research should be conducted further in order to understand how college student sexual knowledge can be improved in order to prevent risky sexual behavior. It is also important to conduct this research in order to determine why differences exist in terms of knowledge and certain aspects of sexual self-efficacy.

Information in the current study could be useful in preventing STDs on college campuses. For example, results indicate that resources used to learn about STDs are not related to STD knowledge. This may potentially lead to future research on intervention strategies and education in terms of sexual knowledge. Findings in this study may allow other researchers to further explore what college students know about STDs and how this knowledge relates to sexual behavior. Although the findings in this study are general, it is interesting to note differences in how resources and knowledge are related to sexual self-efficacy in some instances, but not others. It is also worthy of noting that this study makes a few interesting points about how sexual knowledge impacts sexual behavior. For instance, sexual knowledge was related to participants' 
ability to refuse sexual intercourse and question potential sex partners. On the other hand, sexual knowledge did not impact participants' ability to use a condom during sexual intercourse.

Although some hypotheses were not supported others may serve as references for future research about how differences exist in knowledge and sexual self-efficacy and how to prevent STDs on college campuses. 


\section{References}

Baldwin, J. I., Whiteley, S., \& Baldwin, J. D. (1990). Changing AIDS- and fertility-related behavior: The effectiveness of sexual education. The Journal of Sex Research, 27, 245-263.

Brewer, K. K. (1997). Behavioral preventions of sexually transmitted diseases and unintended pregnancies in college students. (Doctoral dissertation, University of Iowa, 1997). Dissertation Abstracts International, 58, 2666.

Cecil, H., \& Pinkerton, S. D. (1998). Reliability and validity of a self-efficacy instrument for protective sexual behaviors. Journal of American College Health, 47, 113-121.

Çok, F., Gray, L. A., \& Ersever, H. (2001). Turkish university students' sexual behavior, knowledge, attitudes and perceptions of risk related to HIV/AIDS. Culture, Health \& Sexuality, 3, 81-99.

Denson, D. R., Voight, R., \& Eisenman, R. (1994). Self-efficacy and AIDS prevention for university students. International Journal of Adolescence and Youth, 5, 105-113.

Ehrhardt, B. L., Krumboltz, J. D., \& Koopman, C. (2006). Training peer sexual health educators: Changes in knowledge, counseling self-efficacy, and sexual risk behavior. American Journal of Sexuality Education, 2, 39-55.

Goebel-Komala, M. B. (2003). A survey of sexual behavior and sexual risk in university students using Akers' model (Ronald L. Akers). (Doctoral dissertation, Bowling Green State University, 2002). Dissertation Abstracts International, 63, 4964.

Gokengin, D., Yamazhan, T., Ozkaya, D., Aytug, S., Ertem, E., Arda, B., et al. (2003). Sexual knowledge, attitudes, and risk behaviors of students in Turkey. Journal of School Health, 73, 258-263. 
Gold, A. (2004). TALK To Me About Condoms: What college students know and do about STDs. North Dakota Journal of Speech \& Theatre, 17, 52-65.

Hogben, M.,\& Byrne, D. (1998). Using social learning theory to explain individual differences in human sexuality. Journal of Sex Research, 35, 58-71.

Jaworski, B.C., \& Carey, M.P. (2007). Development and psychometric evaluation of a selfadministered questionnaire to measure knowledge of sexually transmitted diseases. AIDS and Behavior, 11, 557-574.

Jones, N. R., \& Haynes, R. (2006). The association between young people's knowledge of sexually transmitted diseases and their behaviour: A mixed methods study. Health, Risk \& Society, 8, 293-303.

MacNair-Semands, R. R., Cody, W. K., \& Simono, R. B. (1997). Sexual behaviour change associated with a college HIV course. AIDS Care, 9, 727-738.

Pearson, J. (2006). Personal control, self-efficacy in sexual negotiation, and contraceptive risk among adolescents: The role of gender. Sex Roles, 54, 615-625.

Peterson, Y., \& Gabany, S. G. (2001). Applying the NIMH multi-site condom use self-efficacy scale to college students. American Journal of Health Studies, 17, 15-20.

Seal, D. W., \& Agostinelli, G. (1996). College students' perceptions of the prevalence of risky sexual behaviour. AIDS Care, 8, 453-466.

Strader, M. K., \& Beaman, M. L. (1991). Comparison of selected college students' and sexually transmitted disease clinic patients' knowledge about AIDS, risk behaviours and beliefs about condom use. Journal of Advanced Nursing, 16, 584-590. 
Synovitz, R.L., Hebert, E., Kelley, R. M., \& Carlson, G. (2002). Sexual knowledge of college students in a southern state: Relationship to sexuality education. American Journal of Health Studies, 17, 163-173.

Templeton, J. H., \& Wilson, G. L. (1992). The effect of educational intervention on attitudes toward selected high risk sexual behaviors. 1-15. (ERIC Document Reproduction Service No. ED350299).

Turner, J. C., Garrison, C. Z., Korpita, E., Waller, J., Abby, C., Hill, W. R., et al. (1994). Promoting responsible sexual behavior through a college freshman seminar. AIDS E Education \& Prevention, 6, 266-277.

Weinstock, H., Berman, S., \& Cates, W., Jr. (2000). Sexually transmitted diseases among American youth: Incidence and prevalence estimates 2000. Perspectives on Sexual and Reproductive Health, 36, 6-10. 
Appendix A

\section{Dear Participant,}

This letter is a request for you to take part in a research project to assess how college student knowledge about sexually transmitted diseases affects college student sexual behavior. This project is being conducted by Brooke Masters, BS in the department of Human Resources and Education at WVU with supervision of Dr. Carol Markstrom, a professor in the College of Human Resources and Education, for a Master's Degree in Educational Psychology with an emphasis in Child Development and Family Studies. Your participation in this project is greatly appreciated and will take approximately 20 minutes to fill out the attached questionnaire. Your involvement in this project will be kept as confidential as legally possible. All data will be reported in the aggregate. You must be 18 years of age or older to participate. I will not ask any information that should leak back to your identity as a participant. Your participation is completely voluntary. You may skip any question that you do not wish to answer and you may discontinue at any time. The survey will be completely anonymous and you will be asked to place it in an envelope after completion. This is to ensure that no one can view your answers on the survey and trace them back to you individually. Your class standing will not be affected if you decide either not to participate or to withdraw. West Virginia University's Institutional Review Board acknowledgement of this project is on file. I hope that you will participate in this research project, as it could be beneficial in understanding the risks associated with sexually transmitted diseases on college campuses. Thank you very much for your time. Should you have any questions about this letter or the research project, please feel free to contact Brooke Masters at (304) 282-9674 or by e-mail at mmaster1 @ mix.wvu.edu.

Thank you for your time and help with this project.

Sincerely,

Brooke Masters 
Appendix B

\section{STD Survey}

These questions are to help researchers understand more about what college students know about STDs and sexual health. Please answer the questions based on what you know. No one will know these are your answers because your name is not on this survey.

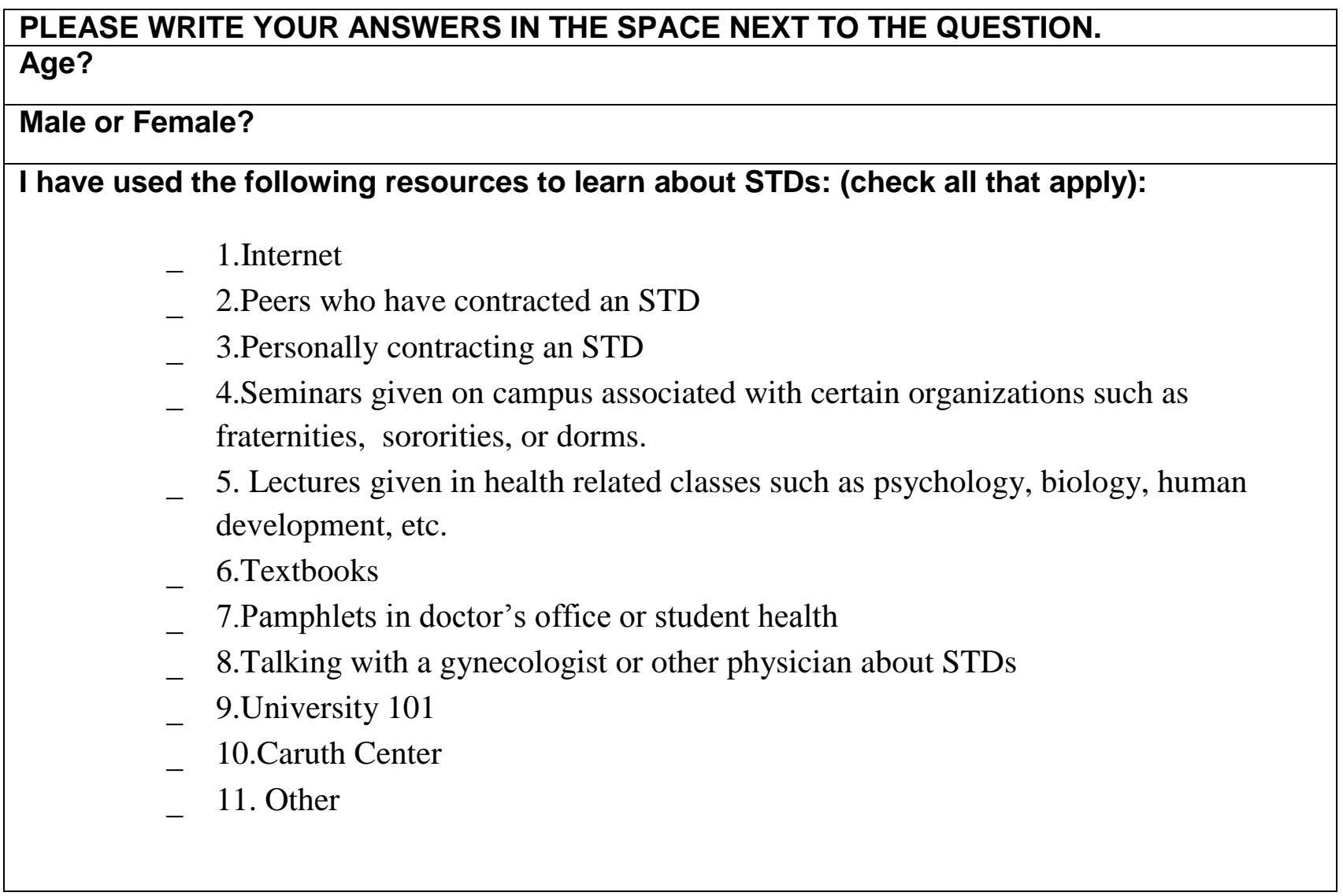




\section{Appendix C}

The Sexually Transmitted Disease Knowledge Questionnaire (STD-KQ; Jaworski \& Carey, 2007)

Instructions: For each statement below, please circle true (T), false (F), or I don't know (DK). If you don't know, please do not guess; instead, please circle DK.

1. T F DK Genital Herpes is caused by the same virus as HIV.

2. T F DK Frequent urinary infections can cause Chlamydia.

3. T F DK There is a cure for Gonorrhea.

4. T F DK It is easier to get HIV if a person has another Sexually Transmitted Disease.

5. T F DK Human Papillomavirus (HPV) is caused by the same virus that causes HIV.

6. T F DK Having anal sex increases a person's risk of getting Hepatitis B.

7. T F DK Soon after infection with HIV a person develops open sores on his or her genitals (penis or vagina).

8. T F DK There is a cure for Chlamydia.

9. T F DK A woman who has Genital Herpes can pass the infection to her baby during childbirth.

10. T F DK A woman can look at her body and tell if she has Gonorrhea.

11. T F DK The same virus causes all of the Sexually Transmitted Diseases.

12. T F DK Human Papillomavirus (HPV) can cause Genital Warts.

13. T F DK Using a natural skin (lambskin) condom can protect a person from getting HIV.

14. T F DK Human Papillomavirus (HPV) can lead to cancer in women.

15. T F DK A man must have vaginal sex to get Genital Warts.

16. T F DK Sexually Transmitted Diseases can lead to health problems that are usually more serious for men than women.

17. T F DK A woman can tell that she has Chlamydia if she has a bad smelling odor from her vagina.

18. T F DK If a person tests positive for HIV the test can tell how sick the person will become.

19. T F DK There is a vaccine available to prevent a person from getting gonorrhea.

20. T F DK A woman can tell by the way her body feels if she has a Sexually Transmitted Disease.

21. T F DK A person who has Genital Herpes must have open sores to give the infection to his or her sexual partner.

22. T F DK There is a vaccine that prevents a person from getting Chlamydia.

23. T F DK A man can tell by the way his body feels if he has Hepatitis B.

24. T F DK If a person had Gonorrhea in the past he or she is immune

25. T F DK Human Papillomavirus (HPV) can cause HIV.

26. T F DK A man can protect himself from getting Genital Warts by washing his genitals after sex.

27. T F DK There is a vaccine that can protect a person from getting Hepatitis B. 
Self-Efficacy Questionnaire: Please respond to statements on a three-part questionnaire regarding sexual selfefficacy by writing a number beside each statement: not at all (1), a little sure (2), somewhat sure (3), pretty sure (4), and very sure (5).

5

Very Sure
3
2 1

A little sure

\section{Refuse Sexual Intercourse}

On a scale of 1 to 5, indicate how sure you are that you would be able to say NO to having sexual intercourse. Next to each item please fill in the blank with the number you have chosen:

\section{YourAnswer}

\begin{tabular}{|c|c|}
\hline 1 & With someone you have known for a few days or LESS? \\
\hline 2 & With someone whose sex and drug history is not known to you? \\
\hline 3 & With someone you have dated for a long time? \\
\hline 4 & With someone you want to date again? \\
\hline 5 & With someone with whom you have already had sexual intercourse? \\
\hline 6 & With someone who you want to fall in love with you? \\
\hline 7 & With someone who is pushing you to have sexual intercourse? \\
\hline \multirow[t]{2}{*}{8} & With someone after you have been smoking marijuana? \\
\hline & $\begin{array}{l}\text { Question Potential Sex Partners: On a scale of } 1 \text { to } 5 \text {; indicate how sure you are that } \\
\text { you would be able to discuss each of the following with your boyfriend/girlfriend. }\end{array}$ \\
\hline 1 & $\begin{array}{l}\text { Ask your boyfriend/girlfriend if he/she has ever injected drugs such as heroin or cocaine into } \\
\text { his/her veins? }\end{array}$ \\
\hline 2 & $\begin{array}{l}\text { Discuss preventing AIDS or sexually transmitted diseases (gonorrhea, etc) or PREGNANCY } \\
\text { with your boyfriend/girlfriend? }\end{array}$ \\
\hline 3 & Ask your boyfriend/girlfriend about sexual relationships that he/she has had in the past? \\
\hline 4 & Ask your boyfriend/girlfriend if he/she has ever had anal (rectal or butt) intercourse? \\
\hline 5 & Ask your boyfriend/girlfriend if he/she has ever had a sexually transmitted disease? \\
\hline
\end{tabular}




\begin{tabular}{|c|l|l|}
\hline & $\begin{array}{l}\text { Condom Use: On a scale of 1 to 5, indicate how sure you are that you would be } \\
\text { able to perform each of the following? }\end{array}$ & \\
\hline 1 & Use a condom correctly? & \\
\hline 2 & Use a condom every time that you had sexual intercourse? & \\
\hline 3 & Use a condom during sex after you have been drinking? & \\
\hline 4 & Use a condom during sex after you have been using marijuana? & \\
\hline 5 & Insist on using a condom during sex, even if your boyfriend/girlfriend doesn't want to? & \\
\hline 6 & Refuse to have sex if your boyfriend/girlfriend will not use a condom? & \\
\hline 7 & Get the money needed to buy condoms? & \\
\hline 8 & Walk into a store and buy condoms? & \\
\hline
\end{tabular}


Table 1

Study Variable Descriptive Statistics and Correlations

\begin{tabular}{|c|c|c|c|c|c|c|c|c|}
\hline & Variable & $\mathrm{M}$ & SD & 1 & 2 & 3 & 4 & 5 \\
\hline 1 & Sources & 4.67 & 1.79 & & & & & \\
\hline 2 & Knowledge & 14.12 & 5.44 & .15 & & & & \\
\hline 3 & Total Self-Efficacy & 79.36 & 12.39 & .14 & $.24 * *$ & & & \\
\hline 4 & Refusal Self-Efficacy & 24.80 & 7.00 & .06 & $.23 *$ & $.80 * *$ & & \\
\hline 5 & Potential Self-Efficacy & 21.95 & 4.30 & $.26 * *$ & $.25 * *$ & $.41 * *$ & .14 & \\
\hline 6 & Condom Self-Efficacy & 32.61 & 6.83 & .02 & .05 & $.73 * *$ & $.34 * *$ & -.03 \\
\hline
\end{tabular}

Note. ${ }^{*} p<.05, * * p<.01$. 
Table 2

Regression - Ability to Refuse Sexual Intercourse

\begin{tabular}{lccc}
\hline & US B & SE & $\beta$ \\
\hline Step 1 & .30 & .12 & $.23^{*}$ \\
Knowledge & & & \\
Step 2 & .29 & .12 & $.23^{*}$ \\
Knowledge & .09 & .36 & .02 \\
Number of Resources & & & \\
Step 3 & .29 & .12 & $.23 *$ \\
Knowledge & .10 & .37 & .03 \\
Number of Resources & -.02 & .07 & -.03 \\
Interaction (Knowledge x Resources) & & & \\
\hline
\end{tabular}

Note. ${ }^{*} p<.05, * * p<.01$. 
Table 3

Regression - Questioning Potential Sex Partners

\begin{tabular}{lccc}
\hline & US B & SE & $\beta$ \\
\hline Step 1 & .20 & .07 & $.25^{* *}$ \\
Knowledge & & & \\
Step 2 & .17 & .07 & $.21^{*}$ \\
Knowledge & .55 & .21 & $.23^{*}$ \\
Number of Resources & & & \\
Step 3 & .17 & .07 & $.21^{*}$ \\
Knowledge & .59 & .21 & $.24 * *$ \\
Number of Resources & & & \\
Interaction (Knowledge x Resources) & -.09 & .02 & -.21 \\
\hline
\end{tabular}

Note. $* p<.05, * * p<.01$. 
Table 4

Regression-Condom Use

US B $\quad$ SE $\quad \beta$

\begin{tabular}{lccc}
\hline Step 1 & .06 & .12 & .04 \\
Knowledge & & & \\
Step 2 & .05 & .12 & .04 \\
Knowledge & .06 & .36 & .02 \\
Number of Resources & & & \\
Step 3 & .05 & .12 & .04 \\
Knowledge & .03 & .36 & .01 \\
Number of Resources & .06 & .06 & .09 \\
Interaction (Knowledge x Resources) & .06 & \\
\hline
\end{tabular}

Note. ${ }^{*} p<.05, * * p<.01$. 
Figure 2

Interaction for Resources and Knowledge

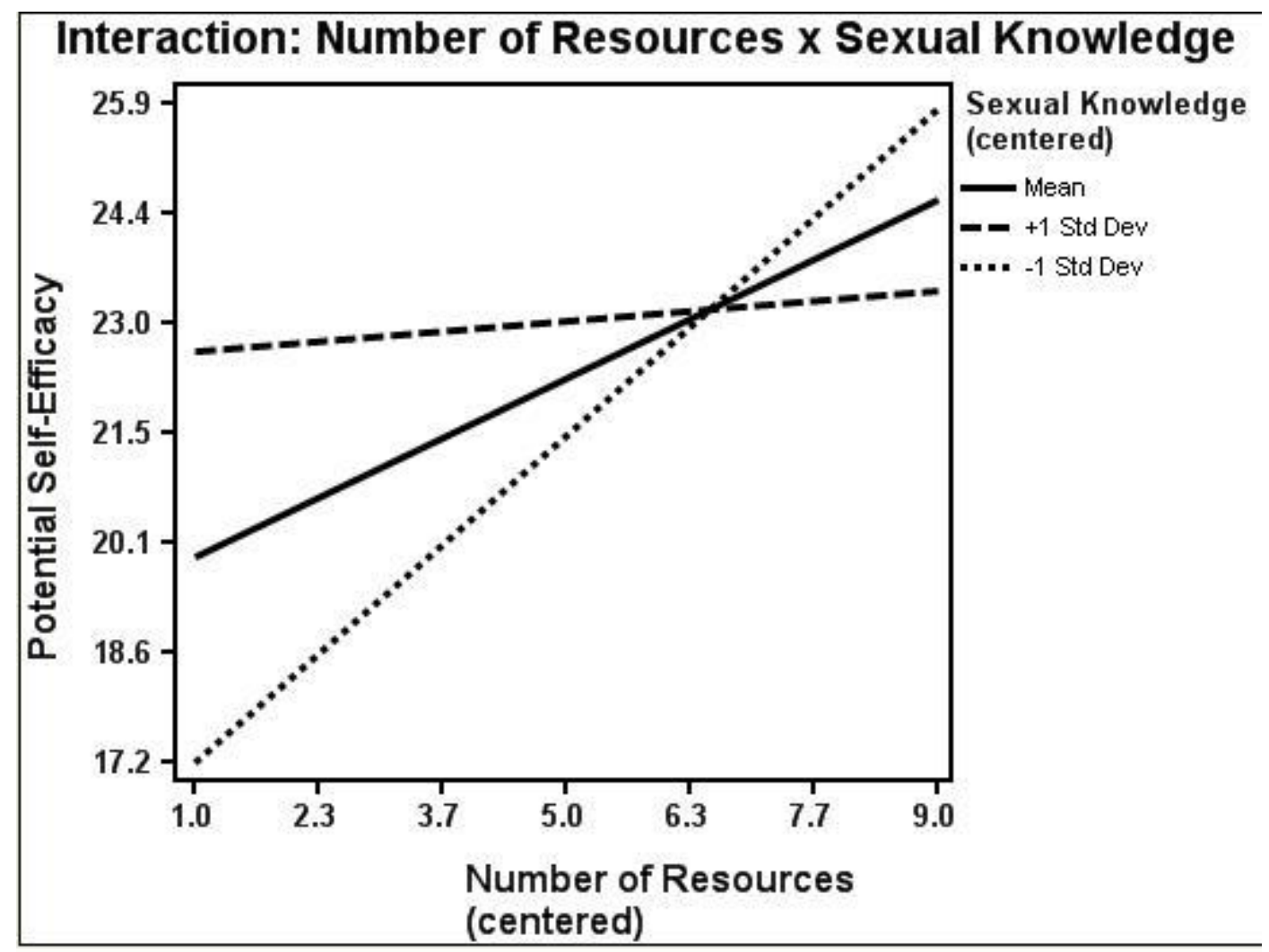

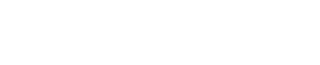

